\title{
Anabases
}

ANABASES Traditions et réceptions de l'Antiquité

18 | 2013

Varia

\section{Edith FOSTER et Donald LATEINER (éd.), Thucydides and Herodotus}

\section{Germaine Aujac}

\section{OpenEdition}

Journals

Édition électronique

URL : http://journals.openedition.org/anabases/4398

DOI : $10.4000 /$ anabases.4398

ISSN : 2256-9421

\section{Éditeur}

E.R.A.S.M.E.

\section{Édition imprimée}

Date de publication : 1 octobre 2013

Pagination : 278-279

ISSN : 1774-4296

\section{Référence électronique}

Germaine Aujac, « Edith foster et Donald LAteiner (éd.), Thucydides and Herodotus », Anabases [En ligne], 18 | 2013, mis en ligne le 01 janvier 2013, consulté le 22 septembre 2020. URL : http:// journals.openedition.org/anabases/4398; DOI : https://doi.org/10.4000/anabases.4398

Ce document a été généré automatiquement le 22 septembre 2020.

(c) Anabases 


\title{
Edith FOSTER et Donald LATEINER (éd.), Thucydides and Herodotus
}

\author{
Germaine Aujac
}

\section{RÉFÉRENCE}

Edith FOSTER et Donald LATEINER (éd.), Thucydides and Herodotus, Oxford, Oxford

University Press, 2012, $399 \mathrm{p}$.

79 livres / ISBN 978-0-19-959326-2.

1 En page de couverture, l'illustration empruntée à un manuscrit de Marcellinus (Vie de Thucydide) met en scène une rencontre imaginaire entre Hérodote lisant son œuvre devant une foule nombreuse et le jeune Thucydide qui le regarde avec intérêt. Voilà qui introduit excellemment le lecteur à ce beau volume qui se propose d'étudier les rapports, trop souvent méconnus, entre ces historiens si proches dans le temps.

Les deux éditeurs, professeurs dans des universités de l'ohio, indiquent dès l'abord leur intention de lutter contre une certaine dévalorisation d'Hérodote au profit de Thucydide considéré comme un modèle, et leur désir de souligner aussi la dette des deux auteurs en prose envers la poésie d'Homère. Ils ont donc réuni une dizaine de spécialistes, américains, anglais ou allemands, avec mission d'illustrer les méthodes de raisonnement des deux historiens, leurs thèmes communs, et leur réception tant chez les Grecs que chez les Romains.

3 Homère le poète est le premier à avoir fourni une description magistrale de la guerre et des conséquences psychologiques qu'elle entraîne sur les participants et même sur les simples témoins. L'Iliade et l'Odyssée constituaient le trésor culturel commun à tous les Grecs ; les historiens n'ont pas manqué de s'en inspirer. R.B. Rutherford (Structure and Meaning in Epic and Historiography, p. 13-38) souligne les affinités entre l'épopée et l'histoire à ses débuts: style, discours, vue sur le monde accusent une incontestable parenté; Thucydide, héritier d'Hérodote, l'est tout autant d'Homère, en particulier dans les livres siciliens. H.P. Stahl (Herodotus and Thucydides on Blind Decisions Preceding 
Military Action, p. 125-153) rappelle que les décisions aveugles dans les affaires de Mélos et de Sicile chez Thucydide, ou de Xerxès au moment d'envahir la Grèce chez Hérodote, avaient des précédents chez Homère; elles eurent dans tous les cas des résultats désastreux. Edith Foster (Thermopylae and Pylos, with reference to the Homeric Background, p. 185-214) évoque avec alacrité la quantité de souvenirs homériques, implicites ou non, que l'on rencontre dans les récits des historiens. Quant à l'utilisation des discours, directs ou indirects, par Hérodote ou Thucydide, elle ne laisse pas de s'inspirer d'Homère, comme le montrent aussi bien Carlo Sandino (Indirect Discourse in Herodotus and Thucydides, p. 67-96) que Christopher Pelling (Aristotle's Rhetoric, the Rhetorica ad Alexandrum, and the speeches in Herodotus and Thucydides, p. 281-315); ce dernier souligne d'ailleurs l'étroite parenté entre rhétorique et historiographie, deux disciplines dont l'objectif est de persuader.

Bien d'autres analyses sont présentées dans cet ouvrage dont l'originalité ne le cède en rien à l'érudition. Donald Lateiner (Oaths : Theory and Practice in the Histories of Herodotus and Thucydides, p. 154-184) étudie le rôle et les différentes formes de serments prêtés au cours des guerres, tant chez Homère, où ils sont nombreux et divers, que chez Hérodote, où ils relèvent surtout de coutumes ethniques, ou chez Thucydide, où serments d'alliance et traités de paix sont souvent peu crédibles et rarement honorés. Wolfgang Blösel (Thucydides on Themistocles : a Herodotean Narrator?, p. 215-240) met en parallèle les opinions divergentes des deux historiens sur Thémistocle, le vainqueur de Salamine mais un homme avide d'argent pour Hérodote, un héros injustement décrié alors qu'il aurait toujours combattu pour Athènes chez Thucydide. Rosario Vignolo Munson (Persians in Thucydides, p. 241-277) montre comment et pourquoi l'opinion de Thucydide sur les Perses a évolué au cours du temps : si l'historien jugeait les Guerres Médiques une affaire courte, vite réglée, et ne prêtait guère attention à la Perse dans les premiers livres de son Histoire, il constatait avec peine et effroi le retour de la menace perse après l'expédition de Sicile; le Grand Roi lui paraitra désormais un dangereux protagoniste, à même de jouer les arbitres dans les conflits entre Grecs. Catherine Rubincan (The "Rationality» of Herodotus and Thucydides as Evidence by Their Respective Use of Numbers, p. 97-122), dans un article fort bien venu en réponse à Paul Keyser, soutient que chez Hérodote, la passion pour l'arithmétique s'exerce sur des données illusoires, et échappe ainsi à la rationalité, tandis que Thucydide se montre beaucoup plus prudent et modéré dans l'évocation des nombres. Quant à Emily Baragwanath (A Noble Alliance: Herodotus, Thucydides, and Xenophon's Procles, p. 316-344), elle analyse avec pertinence les deux discours de Procles de Phlionte, venu à Athènes intercéder en faveur de Sparte menacée d'une invasion thébaine: les thèmes développés par Xénophon dans ces deux discours, éloge de la petite cité de Phlionte, sa loyauté envers Sparte, ses vertus de fidélité, de générosité, de force d'âme, ne diffèrent guère de ceux évoqués dans des occasions semblables par Hérodote ou Thucydide. C'est Iris Samotta (Herodotus and Thucydides in Roman Republican Historiography, p. 345-378) qui conclut cet intéressant recueil en s'attachant à montrer que la bataille de Pydna (168), où le roi de Macédoine Persée fut vaincu par Paul-Émile, n'a pas marqué un tournant décisif chez les historiens latins, très influencés par leurs prédécesseurs grecs; s'ils avaient au début rédigé leurs ouvrages en grec, comme Quintus Fabius Pictor, ils ont ensuite, à l'exemple de Caton l'Ancien, favorisé la langue latine, comme Quintus Aelius Tuberon, Ciceron ou Salluste, mais les modèles restaient les historiens grecs.

Un index locorum, un index nominum, un index des matières, ainsi que d'abondantes bibliographies à la fin de chaque article, complètent heureusement ce volumineux 
ouvrage dont un si bref compte rendu ne saurait traduire l'exceptionnelle richesse et l'incontestable originalité.

\section{AUTEURS}

GERMAINE AUJAC

Université de Toulouse (UTM)

aujac.germaine@wanadoo.fr 